\title{
AVALIAÇÕES CITOLÓGICAS EM OTITES CANINAS POR MALASSEZIA SPP.: ESTUDO RETROSPECTIVO
}

\author{
Alessandra Melchert ${ }^{1}$, Ana Beatriz Simões Jefery ${ }^{2}$, Rogério Giuffrida ${ }^{1}$ \\ ${ }^{1}$ Docente do Curso de Medicina Veterinária e Programa de Mestrado em Ciência Animal da UNOESTE. ${ }^{2}$ Médica Veterinária autônoma.
}

\section{RESUMO}

A otite externa é uma afecção freqüentemente observada em cães na clínica de pequenos animais. A Malassezia spp. é o microrganismo isolado em maior frequência nos ouvidos de cães, sendo um dos principais agentes etiológicos causadores de infecções otológicas. A identificação deste agente pode ser baseada citologia do cerúmen ou cultura do agente, sendo o último método mais demorado e de maior custo. O objetivo deste trabalho foi realizar um estudo retrospectivo da incidência de Malassezia spp. em casos de otite canina em um período de cinco anos, por meio de citologia. Amostras de cerúmen auricular de 249 cães com suspeita de otite foram avaliadas, observando-se amostras positivas para Malassezia spp. em 44 casos (17,67\%), sendo 35 cães $(79,5 \%)$ com citologia positiva nos 2 ouvidos e 9 cães $(20,5 \%)$ com positividade para a malassezíase em apenas um dos ouvidos. Conclui-se que cães com suspeita de otite apresentam elevada incidência de citologia com contagens positivas para Malassezia spp. A citologia revela-se, deste modo, método útil no diagnostico de otites caninas com envolvimento deste patógeno, representando alternativa diagnóstica naqueles casos onde a realização da cultura é inviável. Entretanto, deve-se considerar que não há padrão nacional citológico da contagem de células de levedura/campo estabelecido para casos de otite canina, o que pode representar possível falha diagnóstica.

Palavras-chave: cães; citologia; infecção fúngica; otite.

\section{CYTOLOGY AVALIATION IN CANINE OTITIS BY MALASSEZIA SPP.: RETROSPECTIVE STUDY}

\begin{abstract}
Otitis externa is a condition frequently observed in dogs at the small animal clinics. Malassezia spp. is the most frequently isolated microorganism in the ears of dogs, which is one of the major etiologic agents of ear infections. Identification of this agent may be based on fungal culture or cytology, and the first method is longer and more expensive. The aim of this study was to conduct a retrospective study of the incidence of Malassezia spp. in cases of canine otitis by cytology, in a period of five years. Ear cytology samples from 249 dogs with suspected otitis were evaluated, and were observed positive samples for Malassezia spp. in 44 cases (17.67\%), among these 35 dogs (79.5\%) with positive cytology in both ears, and 9 dogs (20.5\%) were positive for Malassezia in only one ear. In conclusion, dogs with suspected otitis present high incidence of positive Malassezia spp. cytology counts. Cytology revealed to be a useful tool for diagnosis of canine ear infections involving this pathogen, representing diagnostic alternative in cases where the culture is not feasible. However, one must consider that there is no national standard cytological counting yeast cells/field set for cases of canine otitis, which may represent possible misdiagnosis.
\end{abstract}

Keywords: citology; dogs; fungal infection; otitis. 


\section{INTRODUÇÃO}

Malassezia é um gênero de leveduras lipofílicas, que vive na superfície da pele e algumas mucosas de diversos mamíferos e aves. É um organismo comensal que eventualmente pode agir como patógeno. Atualmente já são conhecidas 13 espécies do gênero Malassezia, doze das quais são lipidiodependentes ( $M$. furfur, M. globosa, M. obtusa, M. restricta, M. sloofiae, $M$. sympodialis, $M$. dermatis, $M$. nana, $M$. japonica, M. yamatoensis, M. eqüina sp. nov., $M$. caprae sp. nov.) e uma espécie não lipidiodependente, M. pachydermatis (LÓPEZ, 2008).

Embora não apresente atividade queratolítica, Malassezia vive sobre a pele ou ao redor dos pêlos, utilizando restos epiteliais ou produtos de excreção como fontes de energia para seu desenvolvimento (OLIVEIRA et al., 2005). Tradicionalmente, as espécies lipidiodependentes têm sido relacionadas com a pele humana, enquanto que na pele de cães, $M$. pachydermatis é a espécie geralmente encontrada (MACHADO, 2010).

M. pachydermatis é uma levedura saprofítica não micelial, lipofílica, comumente encontrada na pele, condutos auditivos, sacos anais, reto e vagina de cães normais (NOBRE et al., 2001). Entretanto, pode atuar como um patógeno oportunista do tegumento e do meato acústico externo (PAPICH, 1998).

Em cães, tem sido comumente associada a quadros clínicos de otites externas e dermatites, estando sua proliferação intensa associada a processos de desequilíbrio local ou sistêmico (MACHADO et al., 2003). A proliferação exagerada da levedura está quase sempre relacionada a uma causa primária, como atopia, alergia alimentar, endocrinopatias, distúrbios de queratinização ou antibioticoterapia prolongada (MEDLEAU; HNILICA, 2003). A diminuição das defesas também pode favorecer a proliferação das leveduras, pois a dermatite por Malassezia, no homem, é freqüentemente observada em indivíduos imunodeprimidos (GUÉHO et al., 1998), assim como em gatos imunossuprimidos, positivos para Leucemia Viral Felina (FeLV) (SIERRA et al., 2000).

As otites externas apresentam causas multifatoriais, capazes de promover alterações locais no ambiente do ouvido, tais como alterações do $\mathrm{pH}$, umidade, temperatura e da própria microbiota, o que facilita o desenvolvimento de agentes secundários e oportunistas, como a Malassezia (NOBRE et al., 1998).

No meato acústico externo, a secreção de grande quantidade de cerúmen forma um substrato para a proliferação das leveduras (NASCENTE, 2006). Alterações na composição lipídica do cerúmen, causadas por doenças dermatológicas de base, contribuem para a colonização oportunista da Malassezia. Com a inflamação, as glândulas ceruminosas (glândulas apócrinas) aumentam em tamanho e tortuosidade. A excessiva secreção destas glândulas hiperplásicas diminui a concentração total de lipídeos no canal auditivo, que remove a barreira protetora presente em ouvidos hígidos. Baixos níveis de ácidos graxos livres na superfície dos lipídeos, em conjunto com aumento dos níveis de triglicerídeos de superfície, favorecem a infecção por Malassezia (GOTTHELF, 2004).

Uma vez que a maioria das infecções de ouvido por Malassezia envolve uma reação de hipersensibilidade de base, esta deve ser identificada e tratada. Em cães jovens, a otite por malassezia pode ser resultado de uma alergia alimentar ou sequela de otocaríase. Em animais de meia idade, atopia ou endocrinopatias são consideradas, bem como as alergias alimentares. Com as dietas alimentares, terapias de hipossensibilização e uso de corticosteróides, o 
sucesso da terapia em longo prazo da otite por Malasszeia pode ser esperado. O uso da Cyclosporina-A modificada (Atopica ${ }^{\circledR}$, Novartis) não tem sido encorajado no tratamento da otite externa por Malassezia (GOTTHELF, 2004).

As otites externas associadas à proliferação da Malassezia geralmente são bilaterais e caracterizadas clinicamente por uma forma eritemato-ceruminosa, às vezes pruriginosas, e eventualmente promovem dor e o balançar constante da cabeça (AUGUST, 1993). De acordo com Leite, Abreu e Costa (2003), o aspecto clínico predominante é a presença de exsudato abundante e de consistência pastosa, com hiperplasia e hiperemia do epitélio do conduto auditivo. O cerúmen é escuro, geralmente abundante, espesso e com odor. A presença de outros organismos é observada e tem freqüentemente predominância de bactérias (NOBRE et al., 2001).

O diagnóstico da otite externa por Malassezia baseia-se na identificação da levedura, pela citologia do cerúmen e cultura do agente (NASCENTE, 2006). A citologia é uma técnica aceitável para diagnóstico de rotina e controle das dermatites e otites causadas por Malassezia em cães, embora seja reconhecida como menos sensível que a cultura fúngica, podendo-se realizar a associação entre exames diretos e culturas fúngicas. O sítio anatômico, a raça e a técnica de coleta devem ser considerados na interpretação dos resultados (BENSIGNOR et al., 2000). A coleta pode ser realizada com um swab da região auricular ou cutânea (GUILLOTT, 1993). Em cães, um número de leveduras excedendo 5-8/campo em objetiva de imersão é considerado significante (GOTTHELF, 2004).

O objetivo deste trabalho foi realizar um estudo retrospectivo da incidência de Malassezia pachydermatis em citologias dos casos de otite canina, no período de janeiro de 2005 a dezembro de 2009.

\section{MATERIAL E MÉTODOS}

O estudo retrospectivo foi realizado a partir dos arquivos do serviço de diagnóstico microbiológico do Hospital Veterinário da Universidade do Oeste Paulista - UNOESTE, Presidente Prudente, SP, durante o período de janeiro de 2005 a dezembro de 2009. Foram avaliadas citologias provenientes de 249 cães de diversas raças, com sintomatologia compatível com otite externa, provenientes do atendimento clínico no Hospital Veterinário da UNOESTE. Após avaliação clínica, foi realizada colheita do material para citologia do ouvido, introduzindo-se uma zaragatoa estéril o mais profundamente possível nos condutos auditivos verticais direito e esquerdo, obtendo-se um total de 498 amostras. Com o material obtido realizou-se esfregaço em lâmina de vidro e posterior observação microscópica.

As lâminas com os esfregaços foram coradas pelo método do panótico rápido. Procedeu-se a contagem de células leveduriformes compatíveis com a morfologia de M. pachydermatis, em aumento de 1000 vezes, com o auxílio do microscópio de luz (YS2T/NIKON ${ }^{\circledR}$ ), onde as células leveduriformes foram quantificadas em 10 campos microscópicos, fazendo-se a média aritmética para obtenção do número de leveduras por lâmina. Os resultados foram classificados de acordo com o número de leveduras encontradas por campo, como descrito a seguir: amostras negativas: 1-10 leveduras/campo ou ausência de leveduras nas contagens; amostras positivas: >10 leveduras/campo (NOBRE et al., 1998). Foi considerada também a ocorrência de contagens positivas em um ou nos dois condutos auditivos. 


\section{RESULTADOS E DISCUSSÃO}

Dos 249 cães avaliados, 44 (17,7\%) apresentaram citologia positiva para Malassezia spp., enquanto 205 animais (82,3\%) apresentaram citologia com até 10 leveduras por campo microscópico (negativas). Dentre os classificados como negativos, $97 \quad(47,3 \%)$ apresentaram contagens entre 1 e 10 leveduras/campo, enquanto $108 \quad(52,7 \%)$ revelaram ausência de leveduras.

Do número total de cães avaliados, 141 (56,6\%) apresentaram presença de Malassezia em pelo menos um dos condutos auditivos, considerando-se aqueles com contagens normais, onde as contagens não excedem a quantidade de 10 leveduras/campo microscópico, uma vez que a Malassezia faz parte da microbiota do ouvido normal (NOBRE et al., 1998), e naqueles com contagens acima do esperado, ou seja, acima de 10 leveduras/campo microscópico, caracterizados por desequilíbrio da microbiota com proliferação excessiva e desencadeamento de reações inflamatórias (NOBRE et al., 1998).

\section{A contagem de leveduras e a} padronização de um ponto de corte que classifique a ocorrência de infecção são fundamentais, uma vez que a presença da
Malassezia é normal na microbiota do ouvido (ANGUS, 2004). No presente estudo, foi observada a presença da levedura em $56,6 \%$ dos cães em pelo menos um dos condutos auditivos, considerando-se aqueles com contagens normais e com contagens acima do esperado, sendo que apenas $17,7 \%$ apresentaram contagens que caracterizam um quadro infeccioso.

Dos 44 animais positivos para Malassezia, 35 (79,5\%) apresentaram citologia positiva nos 2 ouvidos, enquanto 9 cães (20,5\%) apresentaram positividade para a malassezíase em apenas um dos condutos auditivos, revelando que o patógeno quando passa de sua forma comensal para o parasitismo, com instalação de um quadro infeccioso, atinge, em sua maioria, ambos os condutos auditivos. Na tabela 1 estão descritos os resultados dos exames citológicos obtidos do total de 249 cães, nos cinco anos estudados.

TABELA 1: Número de cães com otopatia que apresentaram citologia auricular positiva (contagem de leveduras acima de10 por campo - >10/campo) ou negativa (contagem de leveduras ausente ou abaixo de 10 por campo - 1-10/campo ou ausentes) para Malassezia spp., nos cinco anos do estudo (2005-2009).

\begin{tabular}{cccccc}
\hline $\begin{array}{c}\text { Ano do } \\
\text { estudo }\end{array}$ & $\begin{array}{c}\text { Positivos } \\
\text { (>10/campo) }\end{array}$ & $\begin{array}{c}\text { Positivos } \\
\text { (>10/campo) }\end{array}$ & $\begin{array}{c}\text { Negativos } \\
\text { (1-10/campo) }\end{array}$ & $\begin{array}{c}\text { Negativos } \\
\text { (Ausentes) }\end{array}$ & Total \\
\hline \multicolumn{7}{c}{ 1 ouvido } & 2 ouvidos & & & \\
\hline 2005 & 7 & 9 & 17 & 31 & 64 \\
2006 & 0 & 6 & 16 & 19 & 41 \\
2007 & 0 & 7 & 14 & 14 & 35 \\
2009 & 1 & 4 & 28 & 19 & 52 \\
TOTAL & 1 & 9 & 22 & 25 & 57 \\
\hline
\end{tabular}

\# - cães que apresentaram citologia positiva apenas em um dos condutos auditivos

* - cães que apresentaram citologia positiva nos dois condutos auditivos.

O exame citológico do cerúmen proveniente do conduto auditivo de cães com otite é útil na determinação do agente etiológico envolvido no processo (GINEL et al., 2002). De 
acordo com Leite, Abreu e Costa (2003), a citologia para observação de leveduras de $M$. pachydermatis no ouvido de cães apresenta boa concordância com exames de cultura fúngica. Em comparação com os testes de cultura fúngica, a citologia apresenta menor custo e maior rapidez na obtenção do resultado, apresentando deste modo uma boa relação custo/benefício.

A citologia é um teste simples, rápido e prático de diagnóstico, que deve ser realizado rotineiramente em qualquer paciente que apresente sinais clínicos compatíveis com otite externa. Em medicina veterinária, a avaliação citológica aliada aos sinais clínicos, otoscopia e testes diagnósticos para a doença de base primária, aumenta a chance do diagnóstico de infecções secundárias, bem como na monitoração da progressão da doença e da resposta à terapia. A citologia associada à cultura e testes de sensibilidade, representam o melhor método para a identificação de infecções. No entanto, se somente um teste puder ser realizado, deve-se sempre escolher a citologia (ANGUS, 2004).

Raabe, Mayser e Weib (1998) isolaram as espécies $M$. pachydermatis, $M$. furfur e $M$. sympodialis tanto de ouvido quanto da pele de cães saudáveis. Do mesmo modo, Nardoni et al. (2005) isolaram espécies de Malassezia da pele e ouvidos de gatos hígidos. $\mathrm{O}$ fato de que a Malassezia é parte integrante da microbiota normal dos ouvidos deve colocar os clínicos de pequenos animais em alerta, uma vez que em situações alterações patológicas dos condutos, pode tornar-se um parasita que contribui na patogênese da otite. De acordo com Nobre et al. (1998), a M. pachidermatis faz parte da microbiota da pele e quando ocorrem alterações no microambiente local, como aumento de umidade, temperatura e substrato, há elevação das contagens celulares, com a transição da forma comensal para o parasitismo.
A Malassezia é o agente fúngico que contribui com maior freqüência para os casos de otite canina, possivelmente por que compõe a microbiota comensal do ouvido dos cães, sofrendo proliferação quando favorecida por fatores extrínsecos ou intrínsecos (GRIFFIN, 2006). Estudos que avaliam a citologia como método diagnóstico de otites caninas com envolvimento de Malassezia vêm sendo realizados na última década (GRIFFIN; SCOTT; ERB, 2007). Contagens elevadas de leveduras em exames citológicos são altamente correlacionadas com anormalidades clínicas do conduto auditivo dos cães (GINEL et al., 2002).

Freqüências para isolamento de $M$. pachydermatis na orelha externa de cães com otites, segundo a literatura, é muito variável. Há citações de 3\% a $80 \%$ de animais infectados (BREITWIESER, 1997; LEITE; ABREU; COSTA, 2003; NASCENTE et al., 2004; CAFARCHIA et al., 2005). Neste estudo, 44 cães (17,67\%) apresentaram citologia positiva em um ou nos dois condutos auditivos, sendo que a maioria (35 cães) apresentou as contagens elevadas nos dois ouvidos. A frequência corrobora com a literatura. Entretanto, essa ampla variação descrita na literatura pode ser devida a erro diagnóstico, variabilidade ambiental, fatores predisponentes, metodologia do estudo, entre outros (PFAU, 2005). Deste modo, estudos que avaliem a metodologia de diagnóstico usada em centros de atendimento veterinário, aliados ao estudo regional da variabilidade dos patógenos envolvidos em diferentes doenças, assumem grande importância.

\section{CONCLUSÃO}

Conclui-se que cães com suspeita de otite apresentam elevada incidência de citologia com contagens positivas para Malassezia spp. Apesar de a cultura ser o método preconizado para diagnóstico deste patógeno, o exame 
citológico, realizado a partir de secreção ceruminosa de cães, constitui método útil e barato, representando alternativa diagnóstica para casos onde a realização da cultura é inviável. Entretanto, deve-se considerar que não há padrão nacional citológico da contagem de células de levedura/campo estabelecido para casos de otite canina, o que pode representar possível falha diagnóstica.

\section{REFERÊNCIAS}

ANGUS, J. C. Otic cytology in health and disease. Veterinary Clinics of North America: Small Animal Practice, Philadelphia, v. 34, n. 2, p. 411-424, 2004.

http://dx.doi.org/10.1016/j.cvsm.2003.10.005.

AUGUST, J. R. Otitis externa: una enfermedad de etiologia multifactorial. Veterinary Clinics of North America: Small Animal Practice, Philadelphia, v. 18, n. 4, p. 1-14, 1993.

BENSIGNOR, E.; JANKOWSKI, F.; SEEWALD, W.; TOUATI, F.; DEVILLE, M.; BEN-ZIONI, Y.; $A R Z I, B$. Use of lufenuron for treating fungol infections of dogs and cats: 297 cases (19971999). Journal of the American Veterinary Medical Association, Schaumburg, v. 217, n. 10, p. 1510-1513, 2000.

http://dx.doi.org/10.2460/javma.2000.217.1510.

BREITWIESER, F. Ergebnisse bakteriologischer und mykologischer Untersuchungen bei der otitis externa des Hundes. Tierärztliche Praxis,

Stuttgart, v. 25, p. 257-260, 1997.

CAFARCHIA, C.; GALLO, S.; CAPELLI, G.; OTRANTO, D. Occurrence and population size of Malassezia spp. in the external ear canal of dogs and cats both healthy and with otitis.

Mycopathologia, Dordrecht, v. 160, n. 2, p. 143149, 2005. http://dx.doi.org/10.1007/s11046-0050151-х.
GINEL, P. J.; LUCENA, R.; RODRIGUEZ, J. C.; ORTEGA, J. A semiquantitative cytological evaluation of normal and pathological samples from the external ear canal of dogs and cats. Veterinary Dermatology, Oxford, v. 13, n. 3, p. 151-156, 2002. http://dx.doi.org/10.1046/j.13653164.2002.00288.x.

GHÉHO, E.; BOEKHOUT, T.; ASHBEE, H. R.; GUILLOT, J.; VAN BELKUM, A.; FAERGEMANN, J. The role of Malassezia species in the ecology of human skin and as pathogens. Medical Mycology Journal, Tokio, v. 36, p. $220-229$, 1998.

GUILLOT, J. Importance du genre Malassezia chez les carnivores domestiques. 1993. 84f. Thèse (Docteur Vétérinaire) - École Nationale Vétérinaire d'Alfort, Université Paris.

GOTTHELF, L. N. Diagnosis and treatment of otitis media in dogs and cats. Veterinary Clinics of North America- Small Animal Practice, Philadelphia, v. 34, n. 2, p. 469-487, 2004. http://dx.doi.org/10.1016/j.cvsm.2003.10.007. GRIFFIN, C. E. Otitis techniques to improve practice. Clinical techniques in small animal practice, Philadelphia, v. 21, n. 3, p. 96-105, 2006.

http://dx.doi.org/10.1053/j.ctsap.2006.05.002.

GRIFFIN, J. S.; SCOTT, D. W.; ERB, H. N. Malassezia Otitis Externa in the Dog: The Effect of Heat-fixing Otic Exudate for Cytological Analysis. Journal of Veterinary Medicine. A Physiology, pathology, clinical medicine, Berlin, v. 54, n. 8, p. 424-427, 2007. http://dx.doi.org/10.1111/j.14390442.2007.00938.x.

LEITE, C. A. L.; ABREU, V. L. V.; COSTA, G. M. Freqüência de Malassezia pachydermatis em otite externa de cães. Arquivo Brasileiro de Medicina Veterinária e Zootecnia, Belo Horizonte, v. 55, n. 1, p. 102-104, 2003. 
http://dx.doi.org/10.1590/S0102-

09352003000100016.

LOPES, R. J. Dermatitis canina por Malassezia.

REDVET - Revista electrónica de Veterinaria, v. 9, n. 5, 2008. Disponível em:

$<$ http://www.veterinaria.org/revistas/redvet/n05050 8.html>. Acesso em: 08 jun. 2010.

MACHADO, M. L. S. Malassezia spp na pele de cães: freqüência, densidade populacional, sinais clínicos, identificação molecular e atividade fosfolipásica. 2010. $87 \mathrm{f}$. Tese (Doutorado em Ciências Veterinárias) - Faculdade de Veterinária - Universidade Federal do Rio Grande do Sul, Porto Alegre.

MACHADO, M. L. S.; APPELT, C. E.; FERREIRO, L.; GUILLOT, J. Otites e dermatites por Malassezia spp em cães e gatos. Clínica Veterinária, São Paulo, v. 44, p. 27-34, 2003. MEDLEAU, L.; HNILICA, K. A. Dermatologia de Pequenos Animais: Atlas Colorido e Guia Terapêutico. 1.ed. São Paulo: Roca, 2003. NARDONI, S.; MANCIANTI, F.; RUM, A.; CORAZZA, M. Isolation of Malassezia species from healthy cats and cats with otitis. Journal of Feline Medicine Surgery, London, v. 7, p. 141145, 2005.

http://dx.doi.org/10.1016/j.jfms.2004.07.005.

NASCENTE, P. S. Estudo da população de Malassezia pachydermatis em otite externa canina e avaliação da sensibilidade in vitro e in vivo frente a antifúngicos. 2006. $135 \mathrm{f}$. Tese (Doutorado em Ciências Veterinárias) Faculdade de Veterinária, Universidade Federal do Rio Grande do Sul, Porto Alegre.

NASCENTE, P. S.; NOBRE, M. O.; MEINERZ, A. R. M.; GOMES, F. R.; SOUZA, L. L.; MEIRELES, M. C. A. Ocorrência de Malassezia pachydermatis em cães e gatos. Revista Brasileira de Medicina Veterinária, Rio de Janeiro, v. 26, n. 2, p. 79-82, 2004.
NOBRE, M.; CASTRO, A. P.; NASCENTE, P. S.; FERREIRO, L.; MEIRELES, M. C. A. Occurrency of Malassezia pachydermatis and others infectius agents as cause of external otitis in dogs from Rio Grande do Sul State, Brazil (1996/1997).

Brazilian Journal of Microbiology, Rio de Janeiro, v. 32, p. 245-249, 2001.

http://dx.doi.org/10.1590/S1517-

83822001000300017.

NOBRE, M.; MEIRELES, M. C. A.; GASPAR, L. F.; PEREIRA, D. I. B.; SCHRAMM, R.; SCHUCH, L. F. D.; SOUZA, L. L.; SOUZA, L. S. Malassezia pachydermatis e outros agentes infecciosos nas otites externas e dermatites em cães. Ciência Rural, Santa Maria, v. 28, n. 3 p. 447-452, 1998. http://dx.doi.org/10.1590/S010384781998000300016.

OLIVEIRA, L. C.; MEDEIROS, C. M. O.; SILVA, I. N. G.; MONTEIRO, A. J.; LEITE, C. A. L.; CARVALHO, C. B. M. Susceptibilidade a antimicrobianos de bactérias isoladas de otite externa em cães. Arquivo Brasileiro de Medicina Veterinária e Zootecnia, Belo Horizonte, v. 57, p. 405-408, 2005. http://dx.doi.org/10.1590/S010209352005000300021.

PAPICH, M. G. Optimum strategy for antibacterial therapy. North American Veterinary Conference. Veterinary Proceedings, v. 12, p.607-608, 1998.

PFAU, C. R. Eficácia do sulfeto de selenio em diferentes concentraçőes sobre Malassezia pachydermatis em căes: estudo in vitro e in vivo. 2005. 60 f. Dissertação (Mestrado em Ciências Veterinárias) - Universidade Federal do Paraná, Curitiba.

RAABE, P.; MAYSER, P.; WEIB, R. Demonstration of Malassezia furfur and $M$. sympodialis together with $M$. pachydermatis in veterinary specimens. Mycoses, Berlin, v. 41, p. 
493-500, 1998. http://dx.doi.org/10.1111/j.1439-

0507.1998.tb00712.x.

SIERRA, P.; GUILLOT, J.; JACOB, H.;

BUSSÍERAS, S.; CHERMETTE, R. Fungal flora

on cutaneous and mucosal surfaces of cats

infected with feline immunodeficiency virus or

feline leukemia virus. American Journal of

Veterinary Research, Schaumburg, v. 61, p.

158-161, 2000.

http://dx.doi.org/10.2460/ajvr.2000.61.158. 